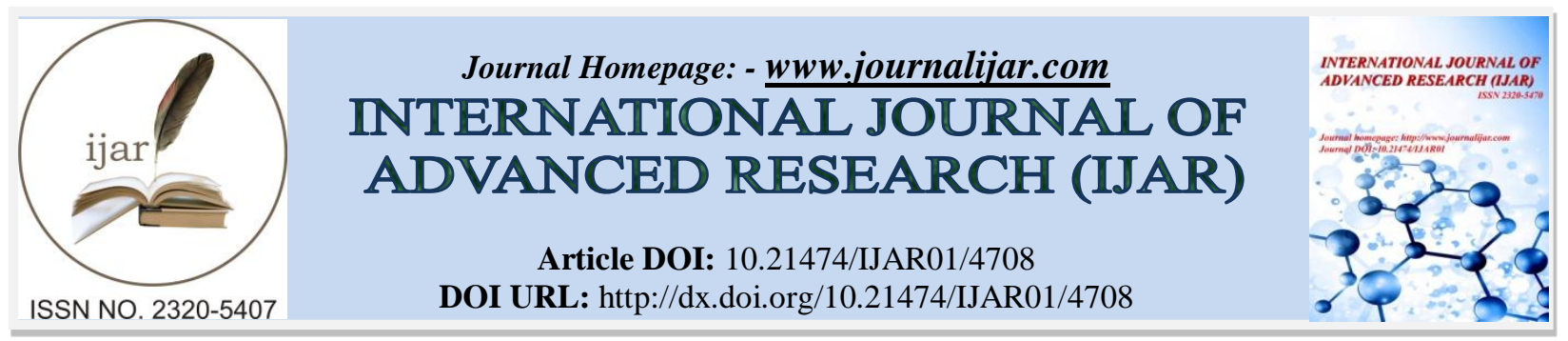

RESEARCH ARTICLE

\title{
CARBOHYDRATE ASSIMILATION PROFILE OF TWO WILD STRAINS OF GENUS CANDIDA IN A MIXTURE OF HEXOSES AND PENTOSES BY ALCOHOL PRODUCTION.
}

\section{Eduardo José Burgos-Valencia ${ }^{1}$, José Alberto Narváez-Zapata ${ }^{2}$, Guadalupe López-Puc ${ }^{1}$, Manuel Octavio Ramírez-Sucre $^{1}$ and ${ }^{*}$ Ingrid Mayanin Rodríguez-Buenfil ${ }^{1}$.}

1. Centro de Investigación y Asistencia en Tecnología y Diseño del Estado de Jalisco, Tablaje Catastral 31264 Km 5.5 Carretera Sierra Papacal-Chuburna Puerto Parque Científico Tecnológico de Yucatán, Merida, Yucatan, México. CP. 97302.

2. Centro de Biotecnología Genómica del Instituto Politécnico Nacional, Boulevard del Maestro s/n esq. Elías Piña, Col. Narciso Mendoza, Cd. Reynosa, Tamaulipas, México. C.P. 88710.

\section{Manuscript Info}

\section{Manuscript History}

Received: 3 May 2017

Final Accepted: 5 June 2017

Published: July 2017

Key words:-

carbohydrate mixtures, assimilation profile, single culture, mixed culture, Candida

\section{Abstract}

Bioethanol is an alternative energy source used as fossil fuel complement. It can be obtained from microbial fermentation of sugars. Efficient fermentations require microorganisms capable of use all the carbohydrates present in raw materials but most of them have different preferences for its assimilation. Mixed cultures are an alternative to perform carbohydrate fermentations due the synergistic combination of different metabolic capacities. In this work the carbohydrate assimilation profile of two Candida glabrata strains (code T1 and LR2) isolated from termite gut and bovine ruminal fluid, respectively, was studied in single and mixed cultures on sugar mixtures. A minimal medium based on nitrogen with $120 \mathrm{~g} / \mathrm{l}$ of carbohydrates (in proportions similar to those found in citric residues) was inoculated with $2.0 \times 10^{7}$ cell $/ \mathrm{ml}$. In mixed cultures (code MC1 and $\mathrm{MC2}$ ), strains were inoculated at proportion 50:50 with the same inoculum concentration. Fermentations were made during ten days at $35^{\circ} \mathrm{C}$ (by T1 single culture and $\mathrm{MC} 1$ ) and $40^{\circ} \mathrm{C}$ (by LR2 single culture and MC2) at $200 \mathrm{rpm}$. LR2 had higher cellular population and biomass and $\mathrm{T} 1$ had better growth rate and doubling time. All the cultures assimilate all sugars. MC1 had the best assimilation of glucose $(94.81 \pm 0.12 \%)$, fructose $(83.83 \pm 0.60 \%)$ and arabinose $(62.12 \pm 0.42 \%)$. T1 single culture had the best assimilation of galactose $(52.64 \pm 0.71 \%)$ and xylose $(56.75 \pm 0.66 \%)$. T1 and MC1 had the best ethanol production $(24.28 \pm 0.78 \mathrm{~g} / \mathrm{l}$ and $24.32 \pm 1.00 \mathrm{~g} / \mathrm{l}$, respectively). MC2 had the highest maximum productivity (6.98 \pm $0.73 \mathrm{~g} / \mathrm{l} \cdot \mathrm{day})$ and alcohol production rate $(0.128 \pm 0.004 \mathrm{~g} / \mathrm{lh})$.

Copy Right, IJAR, 2017,. All rights reserved.

\section{Introduction:-}

Increasing interest in the production of bio-fuel due to the increased demand of energy and fuels, depletion of fossil fuels, concerns about energy security and environmental pollution has led to an interest in the development renewable and sustainable energy sources. Bioethanol is an alternative energy source that can be used as a substitute

Corresponding Author:- Ingrid Mayanin Rodríguez-Buenfil. 
of fossil fuels (Balat and Balat, 2009; Gupta and Verma, 2015; Karmee, 2016). Ethanol is produced in the alcoholic fermentation by microorganisms in which the carbohydrates of a raw material are used by strains to produce alcohol. Vegetable biomass is a raw material of increasing interest to produce ethanol due to the abundancy of the lignocellulosic biomass and the abundance of residues of vegetable origin. The lignocellulosic biomass contain sugars (hexoses and pentoses) like glucose, galactose, xylose and arabinose (Gupta y Verma, 2015; Achinas and Euverink, 2016). Efficient fermentations need strains able to use all the sugars. Unfortunately, many microorganisms can't use all the pentoses and hexoses or show differential and preferential capacities of consumption for the different sugars. Saccharomyces cerevisiae is one of most used microorganisms in fermentation process because of its high levels of ethanol production. This yeast is able to use hexoses but it can't use efficiently pentoses like xylose and arabinose that are main sugars in the lignocellulosic biomass. Other microorganisms are able to use hexoses and pentoses, like Pachysolem tannophilus, Scheffersomyces stipitis, Kluyveromyces marxianus and Candida shehatae, but requires strict conditions like control in the aeration level, substrate concentrations, nutritional factors, etc. Conversion of pentoses to ethanol in yeast occurs through a serie of biochemical redox reactions that conducts to the intermediate D-xylulose, which proceeds to the pentose phosphate pathway and later to the glycolysis pathway and alcohol production through phosphorylation to D-xylulose-5-phospate by xylulose kinase (XK). S. cerevisiae doesn't have some of the enzymes of the catabolism of pentoses or have copies with low activity, like xylose reductase (XR) and xylitol dehydrogenase (XHD) (Girio et al., 2010; Chandel et al., 2011; Tesfaw and Assefa, 2014). Despite the physiologic capacity of pentose-fermenting microorganisms, normally they present preferences for others sugars like the glucose over pentoses. In sugar mixtures the assimilation capacity of a certain strain can change in function of its preference of carbohydrates. This leads to an incomplete and inefficient fermentation of non-glucose sugars and low productivities. Pentose-fermenting yeasts have a retard in consumption of pentoses in glucose/pentoses mixtures and they present a diauxic growth. Also, other yeasts like S. cerevisiae present different assimilation of hexoses in mixtures. This strain can use glucose, fructose and sucrose, but in presence of a mixture of these sugars the fermentation usually doesn't occurs completely. The yeasts consume fructose when glucose is finished. At this point, ethanol concentration and others inhibitors are high and poison the yeast, leading to an incomplete utilization of the fructose. Also, fructose has catabolite repression by glucose (Jasman et al., 2012). There are different ways to overcome the problem of incomplete utilization of the carbohydrates. Some microorganisms can co-ferment carbohydrates like cellobiose and xylose (Lipomyces starkeyi, Cryptococcus curvatus) or glucose and xylose (Trichosporum cutaneum) simultaneously (Zhang et al., 2015). The use of strategies of metabolic or genetic engineering is another way to improve the carbohydrate assimilation and the co-fermentation of different sugars. Another strategy is the use of mixed cultures of strains with different metabolic capabilities for carbohydrate assimilation due the synergic effect of combination of metabolism of two or more strains, and additionally perform the ethanol production. Additional advantages of mixed cultures over single cultures are: compounds and growth factor produced for microorganisms in the mixture can benefit or complement each other and exclude unwanted microorganisms and mixed cultures enable the utilization cheap substrates (Bader et al., 2010; Jasman et al., 2013; Gutiérrez-Rivera et al., 2015; Jahnke et al., 2016). With all above, it's important to know the assimilation profile of carbohydrates in order to do better fermentation strategies and better designs of mixed cultures.

One advantage of the use of mixed cultures is to avoid the use of patented microorganisms due the possibility of use wild strains. The search of microorganisms capable of utilize cellulosic and hemicellulosic carbohydrates materials is important due to the biotechnological potential to use lignocellulosic biomass to produce biofuels like bioethanol. Natural niches like the gut of xylophage insects and the rumen are potential sources of novel microorganisms and enzymes with cellulolytic and hemicellulolytic activity. The termite gut is a niche in which microorganisms like bacteria, yeast and protozoa live in symbiosis and many of them use cellulose and hemicellulose of the wood biomass (Prillinger et al., 1996; Schäfer et al., 1996; Brune, 2014). On the other hand, rumen is a part of the digestive system with an anoxic environment with a complex ecosystem that contains bacteria and fungi that live in symbiosis and contain a complex enzymatic machinery that allow them the hydrolysis and fermentation of cellulosic and hemicellulosic carbohydrates (Christopherson and Suen, 2013; Zorec et al., 2014).

Candida is a genus of yeasts wich some of the species are pentose-fermenting strains (e.g., $C$. shehatae, $C$. guillermondii and $C$. tropicalis) and they are used in fermentation of lignocellulosic feedstocks and mixture of sugars to produce ethanol, alone or in mixed cultures (Acourene and Ammouche, 2012; Hickert et al., 2013; Thongdumyu et al., 2014; Hermansyah et al., 2016; Sopandi and Wardah, 2017). Candida genus comprises over 150 species ubiquitous around the world. Some species are commensals and/or pathogens for humans and grow as yeast or as filamentous type growth (hyphae or pseudohyphae) (Brunke and Hube, 2013; Rodrigues et al., 2014). $C$. 
glabrata is an asexual facultative aerobic and haploid yeast that generally grows as blastoconidia cells. This yeast has been used for the production of metabolites like pyruvate and surfactants (Brunke and Hube, 2013; Rodrigues et al., 2014; Li et al., 2016; Lima et al., 2017). In this work the carbohydrate assimilation and fermentation capacities of two strains of $C$. glabrata isolated from termite stomach (named T1) and ruminal bovine fluid (named LR2) were studied in a sugar mixture of glucose, fructose, galactose, arabinose and xylose in single and mixed cultures in order to determine its assimilation profiles alone and together for these carbohydrates during the production of ethanol.

\section{Materials and Methods:- \\ Strains and Media:-}

The strain $C$. glabrata LR2 was isolated from bovine ruminal fluid and C. glabrata T1 (NRRL Y-50877) was isolated from termite stomach. Yeast strains were propagated in $100 \mathrm{ml}$ of YPD broth containing $10 \mathrm{~g} / \mathrm{l}$ yeast extract (BD, United States of America), $20 \mathrm{~g} / 1$ peptone from casein (Fluka Analytical, Switzerland) and $20 \mathrm{~g} / \mathrm{l}$ dextrose (Meyer, Mexico). The fermentation media was prepared according to a minimal medium yeast nitrogen base (Atlas, 2010) as follows: $5 \mathrm{~g} / 1\left(\mathrm{NH}_{4}\right)_{2} \mathrm{SO}_{4}$ (Sigma, United States of America); $1 \mathrm{~g} / \mathrm{KH}_{2} \mathrm{PO}_{4}$ (Karal, Mexico); $0.5 \mathrm{~g} / 1$ $\mathrm{MgSO}_{4} \cdot 7 \mathrm{H}_{2} \mathrm{O}, 0.1 \mathrm{~g} / \mathrm{l} \mathrm{CaCl} 2,0.4 \mathrm{mg} / 1 \mathrm{ZnSO}_{4} \cdot 7 \mathrm{H}_{2} \mathrm{O}, 0.4 \mathrm{mg} / 1 \mathrm{MnSO}_{4} \cdot \mathrm{H}_{2} \mathrm{O}, 0.04 \mathrm{mg} / 1 \mathrm{CuSO} \cdot 5 \mathrm{H}_{2} \mathrm{O}(\mathrm{J} . \mathrm{T}$. Baker, United States of America); $0.1 \mathrm{~g} / 1 \mathrm{NaCl}$ (CTR, Mexico); $1 \mathrm{mg} / 1 \mathrm{KI}, 0.5 \mathrm{mg} / 1 \mathrm{H}_{3} \mathrm{BO}_{3}, 0.2 \mathrm{mg} / 1 \mathrm{Na}_{2} \mathrm{MoO}_{4} \cdot 2 \mathrm{H}_{2} \mathrm{O}$ (Fermont, Mexico); $0.2 \mathrm{mg} / \mathrm{FeCl}_{3}$ (Sigma-Aldrich, United States of America) and a mixture of carbohydrates as carbon source with a total concentration of $120 \mathrm{~g} / \mathrm{l}$ in a proportion similar to those found in citrus residues (Wilkins et al., 2005; Boluda-Aguilar and López-Gómez, 2013): 51\% glucose, 2\% xylose (Sigma-Aldrich, United States of America); 30\% fructose (Sigma, United States of America); 8\% galactose, 7\% arabinose (Fluka Analytical, Switzerland); $2 \%$ sucrose (BD, United States of America). The $\mathrm{pH}$ of all the medias was adjusted at 4.5 with concentrated $\mathrm{HCl}$.

\section{Inoculum Preparation:-}

A flask containing $100 \mathrm{ml}$ of YPD medium was inoculated with $3 \mathrm{ml}$ of YPD-glycerol (60:40 v:v)-conservated strains with a concentration of $1.0 \times 10^{9}$ cells $/ \mathrm{ml}$ of the strain C. glabrata T1 or LR2 and then incubated at $35^{\circ} \mathrm{C}$ with constant agitation on an orbital shaker at $200 \mathrm{rpm}$ for $6 \mathrm{~h}$ until reaching the log phase (monitored by cell growth). A sample of each flask was taken at $6 \mathrm{~h}$ to obtain and estimate the number of cells using a Neubauer chamber, reaching approximately $4.0 \times 10^{8}$ cells $/ \mathrm{ml}$. The culture from each flask was divided into Falcon tubes of 50 $\mathrm{ml}$ and centrifuged at $4700 \mathrm{rpm}$ with a temperature of $4^{\circ} \mathrm{C}$ for $20 \mathrm{~min}$. Cell pellets were washed two times with sterile $\mathrm{NaCl} 0.85 \%$ and resuspended in the minimal medium with carbohydrates.

\section{Fermentation in synthetic media with mixture of Carbohydrates:-}

Fermentations were carried out in minimal medium yeast nitrogen base with a mixture of carbohydrates (hexoses and pentoses) as carbon source. An aliquot of each cell resuspension in yeast nitrogen base medium with carbohydrates was used for the inoculation of sterile flasks containing synthetic medium. There were a total of four cultures: a single culture of $C$. glabrata T1, a single culture of $C$. glabrata LR2, and two mixed cultures, namely $\mathrm{MC} 1$ and MC2 where the only difference between them was the incubation temperature. Each culture had an initial population of $2.0 \times 10^{7}$ cells $/ \mathrm{ml}$ in $300 \mathrm{ml}$ of synthetic medium. In the mixed cultures, both strains were inoculated at a proportion of 50:50 simultaneously $\left(1.0 \times 10^{7}\right.$ cells $/ \mathrm{ml}$ of each strain). The individual culture of $C$. glabrata T1 and the mixed culture MC1 were incubated at $35^{\circ} \mathrm{C}$. The individual culture of LR2 and the mixed culture MC2 were inoculated a $40^{\circ} \mathrm{C}$. All the cultures were in constant agitation on a rotary shaker at $200 \mathrm{rpm}$ during $240 \mathrm{~h}$. All experiments were performed in duplicate. Samples $(15 \mathrm{ml})$ were taken at different times and were used for monitoring the cellular growth and determination of biomass (dry weight), carbohydrates and ethanol.

\section{Growth Determination:-}

To determine the growth of the cultures, $15 \mathrm{ml}$ of sample was taken of each flask at $0,16,24,40,48,64,72,88,96$, $120,144,168,192,216$ and $240 \mathrm{~h}$ and $0.5 \mathrm{ml}$ of the sample was utilized for the estimation of the cellular population by direct counting cell under the microscope in a Neubauer chamber. The other $14.5 \mathrm{ml}$ were used for determination of biomass as dry weight. The sample was centrifuged at $4700 \mathrm{rpm}$ and $4^{\circ} \mathrm{C}$ for $20 \mathrm{~min}$. Cell pellet was washed two times with sterile distillated water and dried over an aluminum tray in an oven at $80^{\circ} \mathrm{C}$ to constant weight. The supernatant was stored at $-20^{\circ} \mathrm{C}$ until carbohydrates and ethanol analysis.

\section{Carbohydrates Determination:-}

Concentration of the sugars (glucose, fructose, galactose, arabinose and xylose) was determined by Ultra Performance Liquid Chromatography (UPLC) coupled to mass spectrometer (MS). Supernatants were diluted in a 
range from 200 fold to 2 fold with ultrapure water, according to the carbohydrate concentrations expected, and filtered through Phenex-PTFE (polytetrafluoroethylene) membrane syringe filters $(0.2 \mu \mathrm{m}$ pore size and $15 \mathrm{~mm}$ diameter, Phenomenex, United States of America). The analysis was made with an Acquity UPLC H-Class system equipped with a Xevo TQ-S MS detector (Waters, United States of America) using a column Acquity UPLC BEHAmide (150 mm x $3.0 \mathrm{~mm}$ i.d., $1.7 \mu \mathrm{m}$ particle size, Waters, United States of America). The temperature of the column was $35^{\circ} \mathrm{C}$ and the samples $(0.2 \mathrm{ml}$ in duplicate) were injected in the system and eluted at a flow rate of 0.2 $\mathrm{ml} / \mathrm{min}$ during $25 \mathrm{~min}$. A gradient elution was carried out with a mixture of solvent A (acetonitrile: water 30:70 with $0.1 \% \mathrm{NH}_{4} \mathrm{OH}$ ) and $\mathrm{B}$ (acetonitrile: water 80:20 with $0.1 \% \mathrm{NH}_{4} \mathrm{OH}$ ) as follows: $100 \%(\mathrm{~B})$ at 0 min, $20: 80(\mathrm{~A}: \mathrm{B})$ at 8 min, 25:75 (A:B) at $12 \mathrm{~min}, 40: 60(\mathrm{~A}: \mathrm{B})$ at $18 \mathrm{~min}$, finally 100\% (B) from $18.01 \mathrm{~min}$ to 25 min. The carbohydrates were identified by comparison to retention times and molecular weight of standards of the six sugars (SigmaAldrich, United States of America) that were mixed and quantified with a standard curve performed in triplicate with this mixture.

\section{Ethanol Determination:-}

The ethanol was determined by the spectrophotometric method of potassium dichromate according to EstradaMartinez R. (2013). Briefly, $5 \mathrm{ml}$ of supernatant was added to $5 \mathrm{ml}$ of distilled water and the mixed was distillated until recover $5 \mathrm{ml}$. After, $2 \mathrm{ml}$ of the solution of potassium dichromate (added with $323 \mathrm{ml}$ of sulfuric acid and $33.768 \mathrm{~g}$ of potassium dichromate to distillated water and dilute into a $1000 \mathrm{ml}$ volumetric flask) was added to $1 \mathrm{ml}$ of the distillate and putted in repose during $10 \mathrm{~min}$. Five $\mathrm{ml}$ of distillated water was added and the absorbance was read at $585 \mathrm{~nm}$. The concentration of the alcohol was quantified with a standard curve of ethanol (Sigma-Aldrich, United States of America) generated in duplicate.

\section{Statistical analysis and kinetic parameters Calculation:-}

The parameters cellular population, dry weight, grow rate and maximum growth rate, duplication time, rate of substrate consumption, ethanol production, maximum productivity and rate of ethanol production were calculated as follows:

Cellular population was estimated by direct counting cell under the microscope in a Neubauer chamber and them it was calculated on base of the equation (01):

$$
\text { Cellular population }\left(\frac{\text { cells }}{m l}\right)=\left(\frac{\text { Number of counted cells }}{\text { Number of counted squares of the chamber }}\right)(D)(F)
$$

Where $\mathrm{D}$ is the dilution factor and $\mathrm{F}$ is the chamber factor $\left(0.25 \times 10^{6}\right)$.

Dry weight (biomass) was calculated on base of the equation (02):

Dry weight $\left(\frac{g}{l}\right)=\left(\frac{\text { Final weight-initial weigth }}{\text { Sample volume }}\right)$

Where the sample volume is expressed in liters.

The growth rate $(\mu)$ was calculated on base of the equation (03):

$\mu\left(h^{-1}\right)=\frac{d x}{d t}$

Where $\mathrm{x}$ is the cell concentration in terms of dry cell weight per volume $(\mathrm{g} / \mathrm{l})$ and $\mathrm{dx} / \mathrm{dt}$ is the differential expression of the biomass production respect to the time (h) calculated in each point of the growth kinetic, and the maximum value was the $\mu_{\max }$

The doubling time (Td) was calculated on base of the equation (04):

$\operatorname{Td}(h)=\frac{\operatorname{Ln}(2)}{\mu_{\max }}$

Rate of substrate consumption (rs) of each carbohydrate was calculated on base of the equation (05):

$r S\left(\frac{g}{l h}\right)=-\frac{d S}{d t}$

Where $\mathrm{S}$ is the substrate (sugar) concentration $(\mathrm{g} / \mathrm{l})$ and $\mathrm{dS} / \mathrm{dt}$ is the differential expression of the substrate consumption respect to the time (h) calculated in each point of the kinetic. The maximum value is the rate of consumption reported in this work for each sugar.

Rate of ethanol production (rp) was calculated on base of the equation (06):

$r p\left(\frac{g}{l h}\right)=\frac{d P}{d t}$

Where $\mathrm{P}$ is the product (ethanol) concentration $(\mathrm{g} / \mathrm{l})$ and $\mathrm{dP} / \mathrm{dt}$ is the differential expression of the production of alcohol respect to the time $(\mathrm{h})$ calculated in each point of the kinetic. The maximum value is the rate of production reported in this work. 
Maximum productivity $\left(\mathrm{P}_{\max }\right)$ was calculated on base of the equation (07):

$P_{\text {max }}\left(\frac{g}{\text { lday }}\right)=\frac{\text { Ethanol production }}{\text { time of maximun production }}$

Where the time is expressed in days and the ethanol production in $\mathrm{g} / \mathrm{l}$.

Analysis of variance was carried out by an ANOVA test to determine significant differences between the samples. The statistical level of significance was set at $\mathrm{P} \leq 0.05$ with two replicates $(n=2)$. The data were performed using the software Statgraphics Centurion XVI.

\section{Results and Discussion:-}

Kinetic parameters of growth of single Cultures:-

The yeast $C$. glabrata T1 and LR2 were isolated from termite stomach and bovine ruminal fluid, respectively. Its optimal conditions for fermentation were previously determined at $35^{\circ} \mathrm{C}$ and $200 \mathrm{rpm}$ for $\mathrm{T} 1$ and $40^{\circ} \mathrm{C}$ and 200 rpm for LR2 (Estrada-Martinez R., 2013). It was expected that strains T1 and LR2 had a physiologic capacity to utilize cellulose and hemicellulose sugars (hexoses and pentoses). In this work, these strains were incubated in a sugar mixture of hexoses and pentoses in order to determine their assimilation profiles and the possible future application of them in the fermentation of citrus residues. The growth kinetic parameters of T1 and LR2 in the synthetic medium are shown in Table 1. According to this, the strain C. glabrata LR2 has slightly higher cellular population and maximum biomass compared with the strain $\mathrm{T} 1$. In the other side, the strain T1 presented the major growth rate and the least time of doubling time. However, these differences between the yeasts were not statistically significant.

Table 1:- Kinetic parameters of growth by individual cultures of strains C. glabrata (T1) and C. glabrata (LR2) during ten days of fermentation on synthetic medium with a sugar mixture (51\% glucose, $30 \%$ fructose, $8 \%$ galactose, $7 \%$ arabinose, $2 \%$ xylose and $2 \%$ sucrose).

PARAMETER

C. glabrata T1*
STRAIN

\author{
C. glabrata LR2**
}

$\mathrm{a}, \mathrm{b}$ : different letters in the same line show significant differences between strains $(\mathrm{p}<0.05)$.

$*$ C. glabrata $\mathrm{T} 1$ at $35^{\circ} \mathrm{C}$ and $200 \mathrm{rpm}$

** C. glabrata $\mathrm{LR} 2$ at $40^{\circ} \mathrm{C}$ and $200 \mathrm{rpm}$

Kinetic of the fermentation of single Cultures:-

The consumption of carbohydrates, the alcohol production and the yeasts growth are shown in Fig. 1. Although both strains have been identified as $C$. glabrata, they showed differences between them. Fig. 1 shows that T1 presented slightly higher ethanol production compared with LR2 (24.28 $\pm 0.78 \mathrm{~g} / 1$ compared with $21.36 \pm 1.41 \mathrm{~g} / \mathrm{l})$, in contrast, this strain reached the maximum production more quickly than T1 (3.7 days for LR2 compared with 6 days for T1). Both strains were able to assimilate glucose, fructose, galactose, arabinose and xylose in the minimal medium and produced ethanol. Glucose was the mainly sugar consumed, followed by the fructose, which present a retard of $16 \mathrm{~h}$ in its consumption until $30 \%$ of glucose was consumed. The galactose also had a retard of $16 \mathrm{~h}$ and the xylose of 48 $\mathrm{h}$ in the assimilation by the strain T1 when more than $70 \%$ of glucose was consumed, while LR2 strain consumed the galactose since the beginning and the consumption of xylose had a delay of $24 \mathrm{~h}$ when more than $50 \%$ of glucose was consumed. Both strains consumed arabinose by first. Sucrose was not detected. As can be seen in Fig. 1, strain $\mathrm{T} 1 \mathrm{had}$ a rapid growth in the first $16 \mathrm{~h}$ and then had a slowly growth until $96 \mathrm{~h}$. After this point started to decrease until $144 \mathrm{~h}$, when ethanol reached the maximum production. After this point, alcohol started the assimilation by T1 in parallel with the increase of the cellular population. Strain LR2 started ethanol consumption when reached the 
maximum alcohol production $(88 \mathrm{~h})$. LR2 had a rapid growth in the first $24 \mathrm{~h}$, after this point, the growth stabilized until $72 \mathrm{~h}$ and then the cellular population slowly increased until the end of the fermentation (10 days) in parallel with the ethanol and sugar consumption. Zili et al. (2015) with a culture of a strain of C. glabrata in a rich YP medium with glucose or trehalose produced ethanol and cell growth during the fermentation of the sugars, and after the sugars was exhausted, the ethanol was used as a carbon source. It's reported that C. glabrata it's a yeast that can assimilate glucose and trehalose but not galactose or sucrose due to the lost genes related with the metabolism of these carbohydrates like invertase and genes of the Leloir pathway (Bolotin-Fukuhara and Fairhead, 2014; Zili et al., 2015). Sucrose consumption requires a first hydrolysis with extracellular or intracellular invertases that disrupts it in its constituent monosaccharides glucose and fructose (Gargel et al., 2014; Marques et al., 2016). With respect to galactose, its reported that many genes (GAL1, GAL10, GAL7, GAL3, GAL80, GAL4) of the Leloir galactose metabolisms pathway in yeast were reportedly lost in $C$. glabrata in a reductive evolution process suggested due to the commensal and pathogenic lifestyle (Hittinger et al., 2004). Surprisingly, in this work both strains were able to assimilate the galactose. Further investigation is necessary to verify the assimilation of galactose and sucrose in T1 and LR2. Preez et al. (1986) found that $C$. shehatae used glucose, mannose, galactose, xylose, arabinose and cellobiose in a synthetic media with $20 \mathrm{~g} / \mathrm{l}$ of individual sugars and obtained a $\mu_{\max }$ of $0.14,0.20,0.14,0.14,0.04$ and $0.04 \mathrm{~h}^{-1}$, respectively during the fermentation of the respective sugars with a utilization of substrate near to $100 \%$, except for cellobiose, which utilization was about $75 \%$. In the same media, Pichia stipitis used glucose, mannose, galactose, xylose, arabinose, rhamnose and cellobiose and obtained a $\mu_{\max }$ of $0.23,0.18,0.20,0.22,0.14$, 0.16 and $0.21 \mathrm{~h}^{-1}$, with a utilization of near of $100 \%$. These results, except for the growth rate in arabinose and cellobiose by $C$. shehatae, were higher than those obtained in this work despite the strains growth in a sugar mixture. Preez et al. also found in sugar mixtures with $10 \mathrm{~g} / 1$ of each carbohydrate (glucose, mannose, galactose, xylose and the disaccharide cellobiose) a $\mu_{\max }$ of $0.20 \mathrm{~h}^{-1}$ and $0.22 \mathrm{~h}^{-1}$ for $C$. shehatae and P. stipitis, respectively, while the ethanol production was $13.4 \mathrm{~g} / \mathrm{l}$ after near $40 \mathrm{~h}$ of fermentation and $18.6 \mathrm{~g} / \mathrm{l}$ after near $50 \mathrm{~h}$ of fermentation, respectively. Both strains preferred glucose and observed a retard in the fermentation of mannose, galactose, xylose and cellobiose (cellobiose was not consumed by $C$. shehatae). Mannose, galactose and xylose were consumed by $C$. shehahate after the depletion of glucose while only xylose and cellobiose were consumed by Pichia stipitis after the depletion of glucose. In this study, the growth rate of both strains was lower. Strains T1 and LR2 preferred glucose and the consumption of fructose, galactose and xylose by T1 presented a retard, while LR2 presented a retard in the assimilation of the fructose and xylose (see Fig. 1). Both strains started the assimilation of sugars before the depletion of the glucose. The results of ethanol production were higher for T1 and LR2. More recently, Jasman et al. (2012) studied the fermentation of mixed sugars of glucose, fructose and sucrose by strains of S. cerevisiae. They found that the residual concentration of fructose was higher than the residual concentration of glucose in most of the strains, and the yeast had preference to consume glucose than fructose, similar to the results showed by strains T1 and LR2 in this work. Laplace et al. (1991) found that the fermentative behavior of xylose by C. shehatae and Pichia stipits depends on the oxygen transference rate (OTR). They obtain a $\mu_{\max }$ at $0.24 \mathrm{~h}^{-1}$ and $0.30 \mathrm{~h}^{-1}$ and consumed $100 \%$ of xylose $(50 \mathrm{~g} / \mathrm{l})$ with a OTR of $3.90 \mathrm{~mol} \cdot \mathrm{l}^{-1} \cdot \mathrm{h}^{-1}$ at 50 and $57 \mathrm{~h}$ of fermentation by $C$. shehatae and $P$. stipitis, respectively. Sugar consumption and growth rate decreased in parallel to the reduction of aeration. In anaerobic conditions they obtain a $\mu_{\max }$ of $0.07 \mathrm{~h}^{-1}$ and $0.09 \mathrm{~h}^{-1}$ with $15.6 \%$ and $13.5 \%$ of xylose consumed on $72 \mathrm{~h}$ of fermentation by $C$. shehatae and $P$. stipis, respectively. The ethanol and xylitol also were affected by the level of aeration. Ethanol yield tends to reach a maximum in high levels of aeration while xylitol yield decreased at these conditions. It's known that oxygen supplementation is one factor that affect the xylose metabolism and the flux of the carbon to ethanol production or biomass production (Dussan et al., 2016). In this study it wasn't aeration in the cultures of T1 and LR2. Considering the previous information, in conditions of controlled aeration some of the carbohydrates, like the xylose, could have a better consumption and fermentation by strains T1 and LR2. Further investigation is necessary in order to determine the conditions of aeration for improve the fermentation of the strains.

The search of thermotolerant pentose-fermenting strains is important to reduce the costs of operation and cooling systems, especially in tropical countries. Tanimura et al. (2012) screened natural yeast in different sources to search thermotolerant xylose assimilation microorganisms and found a strain of $C$. shehatae capable of use xylose and glucose for growth and ethanol production at $35-39^{\circ} \mathrm{C}$. The best temperature for ethanol production was $37^{\circ} \mathrm{C}$ with approximately $6 \mathrm{~g} / \mathrm{l}$ and $2.5 \mathrm{~g} / \mathrm{l}$ of ethanol for glucose and xylose fermentation, respectively in synthetic. In contrast, at $39^{\circ} \mathrm{C}$ the capability of production decreased to $1 \mathrm{~g} / \mathrm{l}$ and $0.5 \mathrm{~g} / \mathrm{l}$, respectively. Additionally, this strain was capable of assimilate galactose, sucrose, maltose, trehalose and others sugars, but not arabinose. The strain LR2 had the optimal fermentation at $40^{\circ} \mathrm{C}$. T1 and, specially, LR2, are potential thermotolerant strains. Also, the capacity to 
use pentoses like arabinose and xylose, or sugars like galactose make them interesting for the fermentation of lignocellulosic residues at high temperatures.

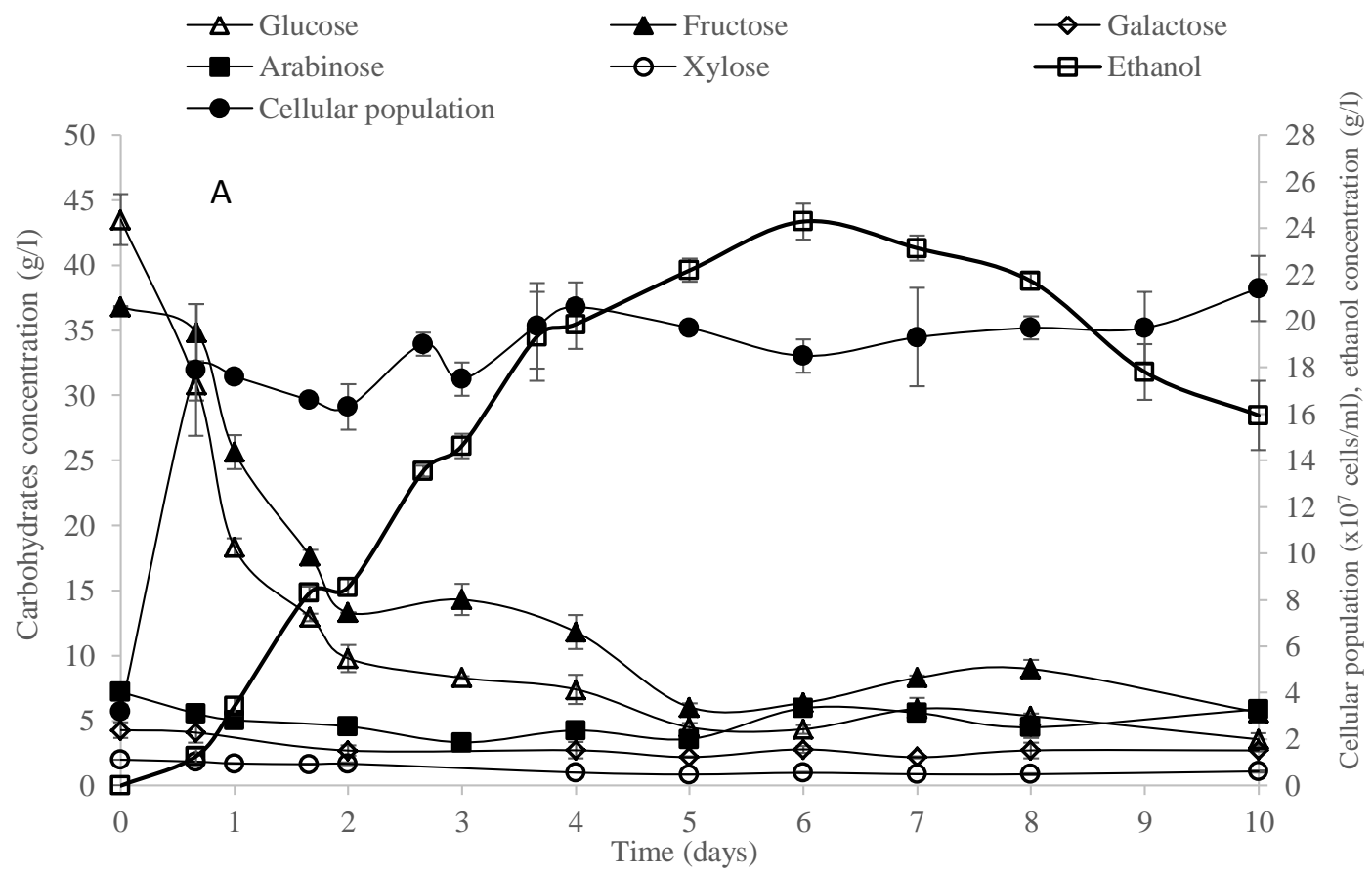

B

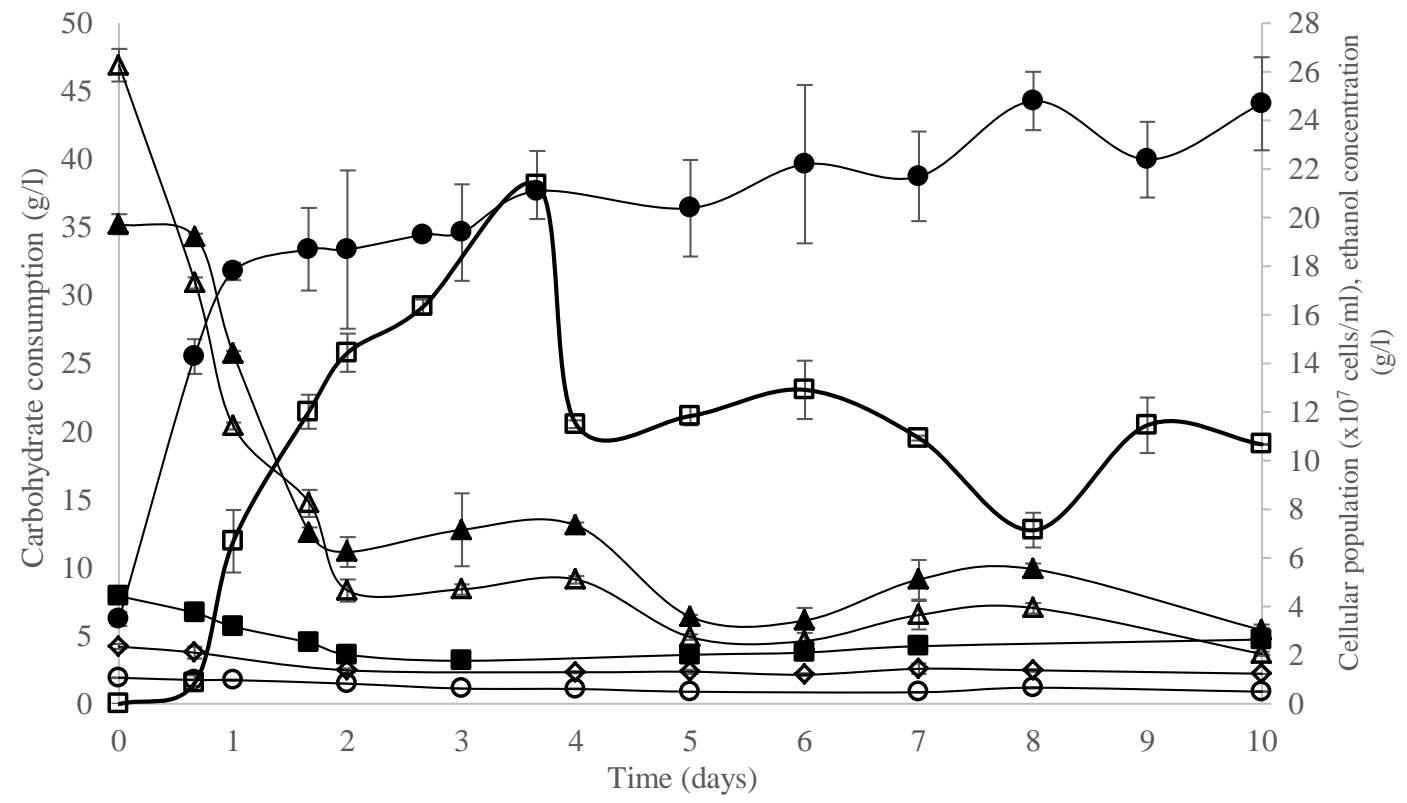

Fig. 1:- Carbohydrate consumption and ethanol production during 10 days of fermentation on synthetic medium with a sugar mixture at $120 \mathrm{~g} / \mathrm{l}$ of carbohydrates $(51 \%$ glucose, $30 \%$ fructose, $8 \%$ galactose, $7 \%$ arabinose, $2 \%$ xylose and $2 \%$ sucrose) by the strain: A) C. glabrata (T1) at $35^{\circ} \mathrm{C}$ and $\left.200 \mathrm{rpm}, \mathrm{B}\right)$ C. glabrata (LR2) at $40^{\circ} \mathrm{C}$ and $200 \mathrm{rpm}$. 


\section{Assimilation percentages and rates of carbohydrate consumption: single and mixed cultures:-}

The percentage of consumption of sugars by both strains in single culture and by the mixed cultures MC1 and MC2 is shown in Fig. 2. The Fig. 3 shows the rate of substrate consumption by all the cultures. As can be seen in Fig. 2, both mixed cultures were capable of assimilate glucose, fructose, galactose, arabinose and xylose. Glucose was the most consumed sugar for all the cultures, followed by fructose at the day of maximum ethanol production. T1 from higher to lower assimilation percentage glucose, fructose, xylose, arabinose and galactose with similar preference of galactose, xylose and arabinose. While for the strain LR2 it was: glucose, fructose, arabinose, galactose and xylose with similar assimilation for galactose and xylose and for fructose and arabinose. For mixed culture MC1 the preference was (in order) glucose, fructose, arabinose, xylose and galactose while by culture MC2 was glucose, fructose, arabinose, galactose and xylose with similar assimilation of fructose, galactose and arabinose. Between cultures, MC1 had the best assimilation of glucose, fructose and arabinose with significant differences. Also, MC1 had a slightly higher consumption of galactose and a better xylose assimilation in comparison with LR2 single culture and with the mixed culture MC2, with significant differences. T1 had the best assimilation for xylose and galactose between cultures with significant differences. LR2 had better consumption of glucose, fructose arabinose and xylose in comparison with culture MC2, and also had similar consumption for galactose. In MC2, the xylose consumption was remarkably lower in comparison with the other three cultures at the $40 \mathrm{~h}$, after this point, the culture continued the carbohydrate assimilation until reach similar percentages to the other cultures (results not shown).

As can be seen in Fig. 3, glucose had the maximum rate of consumption compared with other sugars. Glucose presented the best assimilation and rate of consumption, and as pointed out it was the preferred sugar by all the cultures. The consumption rates of glucose, galactose and arabinose was similar between the four cultures, without significant differences. The rate of assimilation of fructose by MC1 was the lowest and also it had the highest rate of consumption of xylose. MC2 had the lowest rate of assimilation of xylose. The consumption of xylose was lower in comparison with other sugars.

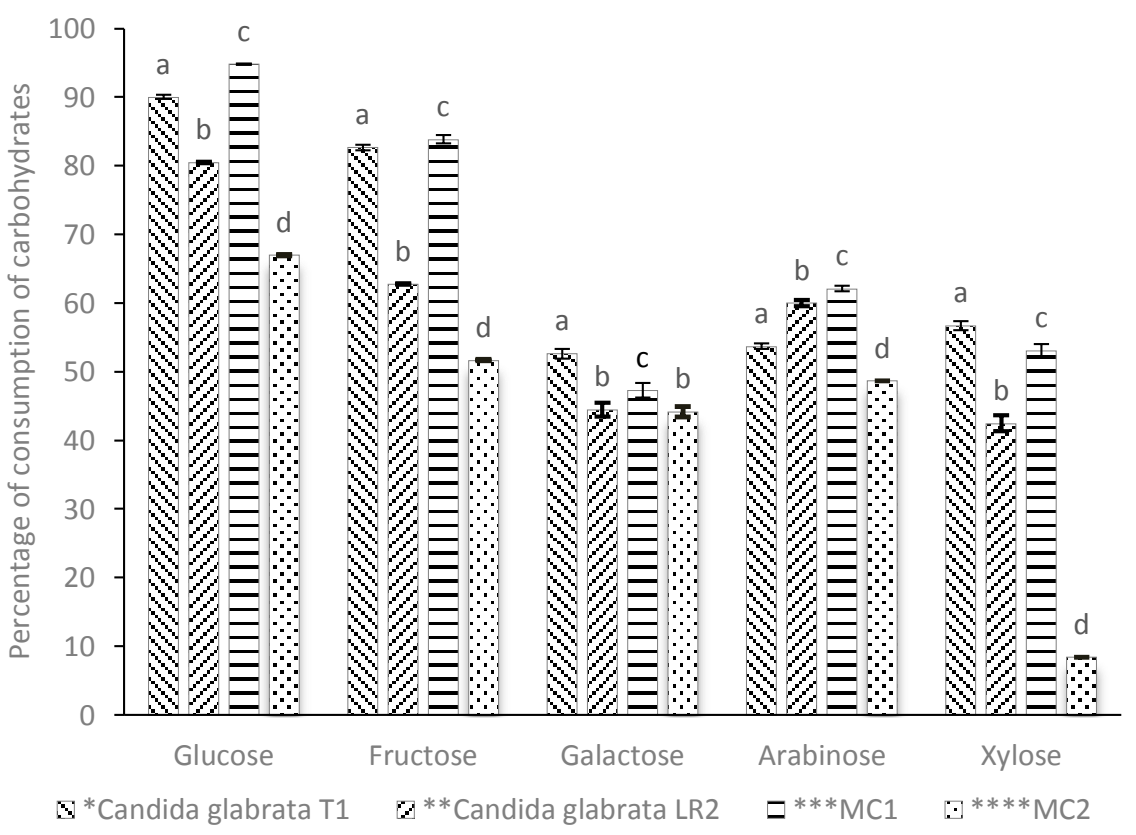

Fig. 2:- Assimilation percentages of the carbohydrates at the maximum production time of ethanol by single and mixed cultures of $C$. glabrata (T1) and $C$. glabrata (LR2) during the fermentation of a synthetic medium with a sugar mixture at $120 \mathrm{~g} / \mathrm{l}$ of carbohydrates ( $51 \%$ glucose, $30 \%$ fructose, $8 \%$ galactose, $7 \%$ arabinose, $2 \%$ xylose and $2 \%$ sucrose).

$\mathrm{a}, \mathrm{b}, \mathrm{c}, \mathrm{d}$ : different letters in the same sugar show significant differences between cultures $(\mathrm{p}<0.05)$.

*C. glabrata $\mathrm{T} 1$ at $35^{\circ} \mathrm{C}$ and $200 \mathrm{rpm}$ 
** C. glabrata LR2 at $40^{\circ} \mathrm{C}$ and $200 \mathrm{rpm}$

***MC1: mixed culture $C$. glabrata T1 and $C$. glabrata LR2 at radio 50:50 with a total cellular population of $20 \mathrm{x}$ $10^{6}$ cells $/ \mathrm{ml}$ inoculated simultaneously at $35^{\circ} \mathrm{C}$ and $200 \mathrm{rpm}$.

****MC2: mixed culture $C$. glabrata $\mathrm{T} 1$ and $C$. glabrata LR2 at radio 50:50 with a total cellular population of $20 \mathrm{x}$ $10^{6}$ cells $/ \mathrm{ml}$ inoculated simultaneously at $40^{\circ} \mathrm{C}$ and $200 \mathrm{rpm}$.

Jeffries and Sreenath (1988) found that in cultures of $C$. shehatae the rate of xylose uptake in mediums of xylose with increasing concentrations of glucose supplements decreased more strongly than the rate of glucose uptake in mediums of glucose with increasing concentrations of xylose supplements. Thus, glucose was more effective for the repression of the xylose assimilation. The rates of consumption were higher than the obtained in this work, because those were obtained in cultures growing in rich medium instead of minimal medium. Most microorganisms have preference for glucose over other sugars and present carbon catabolite repression, expression of genes of enzymes of sugar metabolic pathways and transporters, and/or competence with sugar transporters. Also, expression and activity of the metabolic genes and sugar transporters is influenced by the sugars concentration, so at non-optimal concentrations, the sugar assimilation is reduced or repressed. This is resolved by genetic or metabolic engineering by modified the sugar metabolic pathways or by mixed cultures with microorganisms with different and complementary metabolic capacities (Demir and Kurnaz, 2006; Leandro et al., 2009; Seiboth and Metz, 2011; Marques et al., 2016).

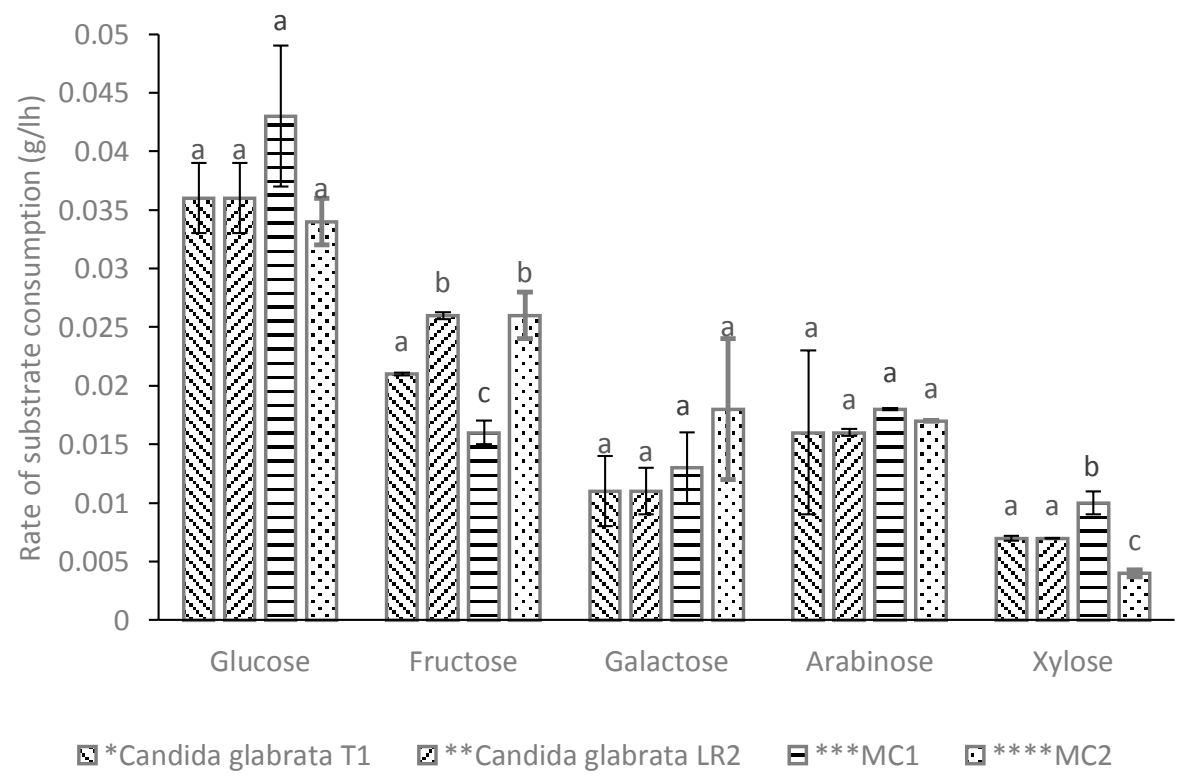

Fig. 3:- Rate of carbohydrate consumption by single and mixed cultures of $C$. glabrata (T1) and C. glabrata (LR2) during the fermentation of a synthetic medium with a sugar mixture at $120 \mathrm{~g} / \mathrm{l}$ of carbohydrates $(51 \%$ glucose, $30 \%$ fructose, $8 \%$ galactose, $7 \%$ arabinose, $2 \%$ xylose and $2 \%$ sucrose).

$\mathrm{a}, \mathrm{b}, \mathrm{c}$ : different letters in the same sugar show significant differences between cultures $(\mathrm{p}<0.05)$.

*C. glabrata $\mathrm{T} 1$ at $35^{\circ} \mathrm{C}$ and $200 \mathrm{rpm}$

** C. glabrata LR2 at $40^{\circ} \mathrm{C}$ and $200 \mathrm{rpm}$

***MC1: mixed culture $C$. glabrata $\mathrm{T} 1$ and $C$. glabrata $\mathrm{LR} 2$ at radio 50:50 with a total cellular population of $20 \mathrm{x}$ $10^{6}$ cells $/ \mathrm{ml}$ inoculated simultaneously at $35^{\circ} \mathrm{C}$ and $200 \mathrm{rpm}$.

****MC2: mixed culture $C$. glabrata T1 and C. glabrata LR2 at radio 50:50 with a total cellular population of $20 \mathrm{x}$ $10^{6}$ cells $/ \mathrm{ml}$ inoculated simultaneously at $40^{\circ} \mathrm{C}$ and $200 \mathrm{rpm}$.

\section{Production parameters of ethanol by single and mixed Cultures:-}

Table 2 shows the parameters of ethanol production. MC1 and T1 had the higher ethanol production and slightly higher production than the single culture of LR2, with no significate difference between the three cultures. These cultures had a higher alcohol production in comparison with culture MC2. On the other side, MC2 produced ethanol with the major production rate and reach the maximum production in less time, i.e. 40 h. Additionally, MC2 had a 
significantly higher maximum productivity in comparison with $\mathrm{MC1}$ and $\mathrm{T} 1$, and slightly higher than LR2 single culture. MC1 had the lowest maximum productivity of all cultures, followed by T1, without significant difference between these two. Moreover, $\mathrm{MC} 1$ had a significant better production rate of ethanol compared with $\mathrm{T} 1$ and similar with LR2. Maybe this reflects the combination of metabolism of different strains in a mixed culture. MC1 had a higher production rate, similar to LR2, but a smaller maximum productivity, reaching the maximum production at 7 days, similar to T1. This possibly is consequence of the growth parameters (Table 1). MC1 was incubated at the optimal ethanol production conditions of $\mathrm{T} 1\left(35^{\circ} \mathrm{C}\right.$ and $\left.200 \mathrm{rpm}\right)$, which had a better growth rate and doubling time at these conditions than LR2 at optimal conditions $\left(40^{\circ} \mathrm{C}\right.$ and $\left.200 \mathrm{rpm}\right)\left(\mu_{\max }: 0.093\right.$ and $0.076 \mathrm{~h}^{-1}$, Td: 7.50 and 9.12 for T1 and LR2, respectively, Table 1). Because of its higher $\mu_{\max }$, T1 grew faster and dominated the fermentation over the time. In consequence, the ethanol production was similar to the alcohol production of T1. The high rate of ethanol production of $\mathrm{MC1}$ probably was consequence of an initial co-fermentation of carbohydrates by both strains that results in a quickly initial production of ethanol. $\mathrm{MC1}$ also had better assimilation of glucose, fructose and arabinose, as mentioned above (Fig. 3), probably because both yeasts contribute to consume the carbohydrates. It's remarkably the better utilization of arabinose by $\mathrm{MC1}$ in comparison with $\mathrm{T} 1$, and the similarity with the assimilation of the sugar by LR2, which presented a preference for this carbohydrate. Moreover, the consumption of xylose by MC1 was higher in comparison with the assimilation by LR2. The efficiency in the consumption of pentoses is important during the production of alcohol by carbohydrates fermentation because the difficult of its metabolism (repressed by glucose), especially in sugar mixtures.

In similar way to $\mathrm{MC} 1$, the results obtained with MC2 reflects the combination of the metabolism of both strains. The lower ethanol production is related with the growth parameter (Table 1). T1 had better growth rate and doubling in comparison with LR2 (at optimal conditions). MC2 was incubated at the optimal fermentation conditions of LR2. Perhaps at this last condition (40| $\left.{ }^{\circ} \mathrm{C}, 200 \mathrm{rpm}\right) \mathrm{T} 1$ had highly parameters of growth in comparison with LR2; at the same time LR2 produced more ethanol. This would establish a competition between alcohol production by LR2 and the growth of $\mathrm{T} 1$ in the mixed culture, and as a consequence, the alcohol production is amortized.

Hickert et al. (2013) used a single culture of $C$. shehatae and a mixed culture of $S$. cerevisiae with $C$. shehatae for ethanol production by a synthetic medium of glucose $(20 \mathrm{~g} / \mathrm{l})$, xylose $(20 \mathrm{~g} / \mathrm{l})$ and arabinose $(10 \mathrm{~g} / \mathrm{l})$. They observed that the single culture was capable of consume the three sugars. Glucose was the preferred sugar consumed and the assimilation of pentoses was retarded; the arabinose assimilation was dramatically retarted until glucose and xylose were exhausted. The production of alcohol was about $23 \mathrm{~g} / \mathrm{l}$ at $100 \mathrm{~h}$, approximately. In the mixed culture, the arabinose was not consumed; but they obtained a production of approximately $13 \mathrm{~g} / \mathrm{l}$ in about $50 \mathrm{~h}$. In comparison, in this study the ethanol production of LR2 $(21.36 \pm 1.41 \mathrm{in} 88 \mathrm{~h})$ was a similar to the alcohol production of $C$. shehatae single culture. In contrast, LR2 was capable to consume the glucose and arabinose since the beginning of the fermentation. Moreover, MC2 had an ethanol production $(11.59 \pm 1.21$ at $40 \mathrm{~h})$ similar to the obtained by these authors with the mixed culture (C. shehatae and S. cerevisiae), in contrast with T1, LR2 and MC1, which had higher alcohol production. The mixed cultures could be improve with a sequential inoculation. Guan et al. (2013) produced ethanol by a mixed culture of $S$. cerevisiae or Brettanomyces bruxellensis both with $C$. shehatae in a sugar mixture of $50 \mathrm{~g} / \mathrm{l}$ of glucose, $40 \mathrm{~g} / \mathrm{l}$ of xylose and $50 \mathrm{~g} / \mathrm{l}$ of cellobiose with a first inoculation of $C$. shehatae for the consumption of glucose and xylose. After $48.5 \mathrm{~h}$, they inoculated the ethanol-tolerant yeast of $S$. cerevisiae that fermented glucose from hydrolyzed cellobiose or a strain of B. bruxellensis, that fermented the cellobiose. With the second strain there was an increment of ethanol production from approximately $33.8 \mathrm{~g} / \mathrm{l}$ to $57.0 \mathrm{~g} / \mathrm{l}$. Similar strategy was adopted by Gutiérrez-Rivera et al. (2015) with a mixed culture of S. stipitis and S. cerevisiae. They evaluated the fermentation in a hydrolysate of sugarcane bagasse supplemented with molasses with simultaneous inoculation of both strains at different inoculum ratios resulting in similar ethanol productions in all the mixed cultures, apparently indicating that the strain of S. stipitis had a predominance in the cultures due to the competition between Crabtree-positive yeast (like S. cerevisiae) and Crabtree-negative yeast (like S. stipitis) during the fermentation of glucose under aerobic conditions. They established a strategy of sequential inoculation, first with S. stipitis (which can use xylose and it's less tolerant to ethanol than $S$. cerevisiae) and after $42 \mathrm{~h}$ with $S$. cerevisiae. The ethanol production was enhanced from approximately $29 \mathrm{~g} / \mathrm{l}$ in simultaneous inoculation to $53.80 \mathrm{~g} / \mathrm{l}$ in sequential inoculation. So, a strategy of sequential inoculation could improve the ethanol production and the utilization of the sugars in mixed cultures of the strains T1 and LR2. The evolution of the population of both strains and its interaction in the mixed culture also must be investigated to improve the fermentation. 
Table 2:- Production parameters of alcohol by single and mixed cultures of $C$. glabrata (T1) and C. glabrata (LR2) during ten days of fermentation on synthetic medium with a sugar mixture (51\% glucose, $30 \%$ fructose, $8 \%$ galactose, $7 \%$ arabinose, $2 \%$ xylose and $2 \%$ sucrose).

\begin{tabular}{|c|c|c|c|c|}
\hline \multirow[t]{2}{*}{ PARAMETER } & \multicolumn{2}{|r|}{ CULTURE } & & \\
\hline & C. glabrata T1* & C. glabrata LR2*** & MC1*** & MC2***** \\
\hline Ethanol $(g / l)$ & $24.28 \pm 0.78^{\mathrm{a}}$ & $21.36 \pm 1.41^{\mathrm{a}}$ & $24.32 \pm 1.00^{\mathrm{a}}$ & $11.59 \pm 1.21^{\mathrm{b}}$ \\
\hline$P_{\max }(g / 1$ day $)$ & $4.05 \pm 0.13^{\mathrm{a}}$ & $5.84 \pm 0.38^{b}$ & $3.47 \pm 0.14^{\mathrm{a}}$ & $6.98 \pm 0.73^{b}$ \\
\hline $\mathrm{rp}(\mathrm{g} / \mathrm{lh})$ & $0.053 \pm 0.001^{\mathrm{a}}$ & $0.079 \pm 0.008^{b}$ & $0.082 \pm 0.004^{\mathrm{b}}$ & $0.128 \pm 0.004^{c}$ \\
\hline Day of max. production & 6.0 & 3.7 & 7.0 & 1.7 \\
\hline
\end{tabular}

$\mathrm{a}, \mathrm{b}, \mathrm{c}$ : different letters in the same line show significant differences between cultures $(\mathrm{p}<0.05)$.

*C. glabrata $\mathrm{T} 1$ at $35^{\circ} \mathrm{C}$ and $200 \mathrm{rpm}$

** C. glabrata LR2 at $40^{\circ} \mathrm{C}$ and $200 \mathrm{rpm}$

***MC1: mixed culture $C$. glabrata T1 and C. glabrata LR2 at radio 50:50 with a total cellular population of $20 \mathrm{x}$ $10^{6} \mathrm{cells} / \mathrm{ml}$ inoculated simultaneously at $35^{\circ} \mathrm{C}$ and $200 \mathrm{rpm}$.

****MC2: mixed culture $C$. glabrata $\mathrm{T} 1$ and $C$. glabrata LR2 at radio 50:50 with a total cellular population of $20 \mathrm{x}$ $10^{6} \mathrm{cells} / \mathrm{ml}$ inoculated simultaneously at $40^{\circ} \mathrm{C}$ and $200 \mathrm{rpm}$.

\section{Conclusion:-}

The assimilation profiles of two strains of $C$. glabrata were studied in single and in two mixed cultures during the fermentation of a carbohydrate mixture of glucose, fructose, galactose, arabinose and xylose in synthetic media. It was found that in single cultures, the strain T1 had higher $\mu_{\max }$ and lower doubling time but the strain LR2 had higher biomass and cellular population. The cultures were capable to consume all the sugars in the mixture, The assimilation profiles during the ethanol production for both strains in single and mixed cultures were different. All the cultures preferred glucose and fructose, but $\mathrm{T} 1$ single culture had similar preference by galactose, arabinose and xylose. LR2 and MC1 preferred arabinose over galactose and xylose and MC2 preferred galactose and arabinose over xylose. Between all the cultures, MC1 had the best consumption of glucose, fructose and arabinose and T1 had the best assimilation of galactose and xylose. Despite both strains were combined in mixed cultures, ethanol production wasn't improved. T1 single culture and MC1 had slightly higher production compared with LR2 single culture but this strain produced ethanol more quickly. MC2 had the lowest alcohol production, the lowest sugar consumption, and the best production rate. Since both strains were inoculated simultaneously in mixed cultures, probably there was a competition due to the differences in growth parameters. The consumption of carbohydrates and alcohol production could be improved with a strategy of mixed cultures with sequential inoculation. The knowledge of the assimilation profiles of both strains in single and mixed cultures will help to search possible use of them in the fermentation of citrus residues.

\section{Acknowledgements:-}

CONACyT Scholarship Burgos-Valencia Eduardo José No. 590286.

\section{References:-}

1. Achinas, S. and Euverink, G.J.W. (2016): Consolidated briefing of biochemical ethanol production from lignocellulosic biomass. Electron. J. Biotechn., 23: 44-53.

2. Acourene, S. amd Ammouche, A. (2012): Optimization of ethanol, citric acid, and $\alpha$-amylase production from date wastes by strains of Saccharomyces cerevisiae, Aspergillus niger, and C. guillermondii. J. Ind. Microbiol. Biotechnol., 39(5): 759-766.

3. Atlas, R. M. (2010): Handbook of Microbiological Media, $4^{\text {th }}$ ed. CRC Press. Taylor \& Francis Group. Boca Raton, FL, USA, pp. 1937-1938.

4. Bader, J., Mast-Gerlach, E. Popović, M.K., Bajpai, R. and Stahl, U. (2010): Relevance of microbial coculture fermentations in biotechnology. Appl. Microbiol., 109(2): 371-387.

5. Balat, M. and Balat, H. (2009): Recent trends in global production and utilization of bio-ethanol fuel. Appl. Energ., 86(11): 2273-2282.

6. Bolotin-Fukuhara, M and Fairhead, C. (2014): Candida glabrata: a deadly companion? Yeast, 31(8): 279288.

7. Boluda-Aguilar, M., López-Gómez, A. (2013): Production of bioethanol by fermentation of lemon (Citrus limon L.) peel wastes pretreated with steam explosion. Ind. Crops and Prod., 41: 188-197.

8. Brune, A. (2014): Symbiotic digestion of lignocellulose in termite guts. Nat. Rev. Microbiol., 12(3): 168-180. 
9. Brunke, S. and Hube, B. (2013): Two unlike cousins: C. albicans and C. glabrata infection strategies. Cell. Microbiol., 15(5): 701-708.

10. Chandel, A.K., Chandrasekhar, G., Radhika, K., Ravinder, R., Ravindra, P. (2011): Bioconversion of pentose sugars into ethanol: A review and future directions. Biotechnol. Mol. Biol. R., 6(1): 8-20.

11. Christopherson, M.R and Suen, G. (2013): Nature's bioreactor: the rumen as a model for biofuel production. Biofuels, 4(5): 511-521.

12. Demir, O. and Kurnaz, I.A. (2006): An integrated model of glucose and galactose metabolism regulated by the GAL genetic switch. Comput. Biol. Chem., 30(3): 179-192.

13. Dussan, K.J., Silva, D.D., Perez, V.H. and da Silva, S.S. (2016): Evaluation of oxygen availability on ethanol production from sugarcane bagasse hydrolysate in a batch bioreactor using two strains of xylose-fermenting yeast. Renew. Energ., 87: 703-710.

14. Estrada-Martínez, R. (2013): Estudio de la capacidad fermentativa de microorganismos silvestres en cultivos mixtos para la producción de alcohol a partir de residuos cítricos: tesis que para obtener el grado académico de Maestro en Ciencia y Tecnología en la Especialidad de Procesos Agroindustriales. Centro de Investigación y Asistencia en Tecnología y Diseño del Estado de Jalisco, Mérida, Yucatán, México.

15. Gargel, C.A., Baffi, M.A., Gomes, E. and Da-Silva, R. (2014): Invertase from Candida stellata strain isolated from grape: production and physicochemical characterization. J. Microbiol. Biotech. Food Sci., 4(1):24-28.

16. Girio, F.M., Fonseca, C., Carvalheiro, F., Duarte, L.C., Marques, S. and Bogel-Łukasik, R. (2010): Hemicelluloses for fuel etanol: A review. Bioresource Technol., 101(13): 4775-4800.

17. Guan, D., Li, Y., Shiroma, R., Ike, M. and Tokuyasu, K. (2013): Sequential incubation of Candida shehatae and ethanol-tolerant yeast cells for efficient ethanol production from a mixture of glucose, xylose and cellobiose. Bioresource Technol., 132: 419-422.

18. Gupta, A. and Verma, J.P. (2015): Sustainable bio-ethanol production from agro-residues: A review. Renew. Sust. Energ. Rev., 41: 550-567.

19. Gutiérrez-Rivera, B., Ortiz-Muñiz, B., Gómez-Rodríguez, J., Cárdenas-Cágal, A., Domínguez-González, J.M. and Aguilar-Uscanga, M.G. (2015): Bioethanol production from hydrolyzed sugarcane bagasse supplemented with molasses "B" in a mixed yeast culture. Renew. Energ., 74: 399-405.

20. Hermansyah, H., Novia, N. and Wiraningsih, M. (2016): Bioethanol production from cellulose by $C$. tropicalis, as an alternative microbial agent to produce ethanol from lignocelullosic biomass. S.J.E., 1(1): 10-13.

21. Hickert, L.R., da Cunha-Pereira, F., de Souza-Cruz, P.B., Rosa, C.A. and Ayub, M.A. Z. (2013): Ethanogenic fermentation of co-cultures of C. shehatae HM 52.2 and Saccharomyces cerevisiae ICV D254 in synthetic medium and rice hull hydrolysate. Bioresource Technol., 131: 508-514.ta

22. Hittinger, C.T., Rokas, A. and Carroll, S.B. (2004): Parallel inactivation of multiple GAL pathway genes and ecological diversification in yeast. Proc. Natl. Acad. Sci. U.S.A., 101(39): 14144-14149.

23. Jahnke, J.P., Hoyt, T., LeFors, H.M., Summer, J.J. and Mackie, D.M. (2016): Aspergillus oryzaeSaccharomyces cerevisiae consortium allows bio-hybrid fuel cell to run on complex carbohydrates. Microorganisms, 4(1): 10.

24. Jasman, J., Prijambada, I.D., Hidayat, C. and Widianto, D. (2012): Selection of yeast strains for ethanol fermentation of glucose-fructose-sucrose mixture. Indones. J. Biotechnol., 17(2): 114-120.

25. Jasman, J., Prijambada, I.D., Hidayat, C. and Widianto, D. (2013): Ethanol fermentation on mixed sugars using coculture of two yeast strains. Indones. J. Biotechnol., 18(2): 116-122.

26. Jeffries, T.W. and Sreenath, H.K. (1988): Fermentation of hemicellulosic sugars and sugar mixtures by $C$. shehatae. Biotechnol. And Bioeng., 31(15): 502-506.

27. Karmee, S.K. (2016): Liquid biofuels from food waste: Current trends, prospect and limitation. Renew. Sust. Energ. Rev., 53: 945-953.

28. Laplace, J.M., Delgenes, J.P., Moletta, R. and Navarro, J.M. (1991): Alcoholic fermentation of glucose and xylose by Pichia stipites, Candida shehatae, Saccharomyces cerevisiae and Zymomonas mobilis: oxygen requirement as a key factor. Appl. Microbiol. Biotechnol., 36(2): 158-162.

29. Leandro, M.J., Fonseca, C. and Gonçalves, P. (2009): Hexose and pentose transport in ascomycetous yeasts: and overview. FEMS Yeast Res., 9(4): 511-525.

30. Li, S., Chen, X., Liu, L. and Chen, J. (2016): Pyruvate production in C. glabrata: manipulation and optimization of physiological function. Crit. Rev. Biotechnol., 36(1): 1-10.

31. Lima, R.A., Andrade, R.F.S., Rodríguez, D.M., Araújo, H.W.C., Santos, V.P. and Campos-Takaki, G.M. (2017): Production and characterization of biosurfactant isolated from C. glabrata using renewable substrates. Afr. J. Microbiol. Res., 11(6): 237-244. 
32. Marques, W.L., Raghavendran, V., Stambuk, B.U. and Gombert, A.K. (2016): Sucrose and Saccharomyces cerevisiae: a relationship most sweet. FEMS Yeast Res., 16(1): fov107.

33. Preez, J.C., Bosch, M. and Prior, B.A. (1986): The fermentation of hexose and pentose sugars by Candida shehatae and Pichia stipitis. Appl. Microbiol. Biotechnol., 23(3): 228-233.

34. Prillinger, H. Messner, R., König, H., Bauer, R., Lopandic, K., Molnar, O., Dangel, P., Weigang, F., Kirists, T., Nakase, T. and Sigler, L. (1996): Yeast associated with termites: a phenotypic and genotyping characterization and use of coevolution for dating evolutionary radiations in asco- and basidiomycetes. System. Appl. Microbiol., 19(2): 265-283.

35. Rodrigues, C.F., Silva, S. and Henriques, M. (2014): C. glabrata: a review of its features and resistance. Eur. J. Clin. Microbiol. Infect. Dis., 33(5): 673-688.

36. Seiboth, B. anf Metz, B. (2011): Fungal arabinan and L-arabinose metabolism. Appl. Microbiol. Biotechnol., 89(6): 1665-1673.

37. Schäfer, A., Konrad, R., Kuhnigk, T., Kämpfer, P., Hertel, H., König, H. (1996): Hemicellulose-degrading bacteria and yeast from the termite gut. J. Appl. Bacteriol., 80(5): 471-478.

38. Tanimura, A., Nakamura, T., Watanabe, I., Ogawa, J. and Shima, J. (2012): Isolation of a novel strain of Candida shehatae for ethanol production at elevated temperature. Springerplus, 1(1): 27.

39. Tesfaw, A., Assefa, F. (2014): Current trends in bioethanol production by Saccharomyces cerevisiae: substrate, inhibitor reduction, growth variables, coculture and immobilization. Int. Sch. Res. Notices., 2014.

40. Sopandi, T. and Wardah, A. (2017): Improving ethanol production by co-culturing of Saccharomyces cerevisiae with C. tropicalis from rice husk hydrolysate media. Afr. J. Microbiol. Res., 11(3): 65-74.

41. Thongdumyu, P., Intrasungkha, N. and Sompong, O. (2014): Optimization of ethanol production from food waste hydrolysate by co-culture of Zymomonas mobilis and $C$. shehatae under non-sterile condition. Afr. J. Biotechnol., 13(7): 866-873.

42. Wilkins, R, Widmer, W.W., Camero, R.G. and Grohmann, K. (2005): Effect of seasonal variation on enzymatic hydrolysis of Valencia orange peel waste. Proc. Fla. State Hort. Soc., 118: 419-422.

43. Zhang G.C, Liu J.J., Kong I.I., Kwak S, Jin Y.S. (2015): Combining C6 and C5 sugar metabolism for enhancing microbial bioconversion. Curr. Opin. Chem. Biol., 29: 49-57.

44. Zili, D.M.W., Lopes, R.G., Alves Jr., S.L., Barros, L.M., Miletti, L.C. and Stambuk, B.U. (2015): Secretion of the acid trehalase encoded by the CgATHI gene allows trehalose fermentation by Candida glabrata. Microbiol. Res., 179: 12-19.

45. Zorec, M., Vodovnik, M. and Marinšek-Logar, R. (2014): Potential of selected rumen bacteria for cellulose and hemicellulose degradation. Food Technol. Biotechnol., 52(2): 210-221. 